\title{
EFFECT OF SEASON ON HELMINTH LOADS OF WILD HERBIVORES AND CATTLE IN THE MUDUMALAI WILDLIFE SANCTUARY, SOUTHERN INDIA.
}

\author{
Guha Dharmarajan ${ }^{1}$, M. Raman ${ }^{2}$ and Mathew C. John ${ }^{3}$ \\ ${ }^{1}$ Centre for Ecological Science, Indian Institute of Science, Bangalore, Karnataka 560012, India \\ 2 Deparment of Parasitology, ${ }^{3}$ Department of Wildlife Science, Madras Veterinary College, Tamil Nadu Veterinary and Animal Sciences \\ University, Chennai, Tamil Nadu 600007, India \\ Email:1guha_d@yahoo.com
}

\begin{abstract}
The effects of season on helminth loads was studied between May and August 1999, using the estimation of helminth eggs per gram of faeces as an index, at the Mudumalai Wildlife Sanctuary, southern India. The species of hosts sampled included chital (Axis axis), gaur (Bos gaurus), elephant (Elephas maximus) and domestic cattle. In general all species showed an upward trend (i.e., the helminth loads increased) as the dry season progressed into the wet. Chital sampled in the dry deciduous forest, with or without sympatric cattle grazing, however, showed no such trends. Chital sampled in scrub forest areas with sympatric cattle grazing showed a significant downward trend as the wet season progressed. It is hypothesised that this is because helminth loads in chital are governed more by nutritive status of the animals rather than the availability of infective larvae in the environment. With the progress of the rains increased vegetation may improve the nutritive status of chital thus causing reduction in helminth loads. Possible reasons for this finding are also discussed.
\end{abstract}

\section{KEYWORDS \\ Axis axis, cattle, chital, epidemiology, helminth loads, season, wild herbivores}

External environmental factors have long been known to affect the helminth loads in the host species. The main route through which the environment influences parasitism is through its effect on stages of the parasite's life cycle that are outside the host, like larvae (Gordon, 1948). However, these effects are not always simple, but can be complicated by interactive effects between the environment, host and parasite (see Poulin, 1996). An external factor that has been shown to affect helminth loads in the wildlife host is season (Horak, 1981; Foreyt \& Trainer, 1980; Waid et al., 1985). Watve (1992) and Bhatt (1994) have studied these effects in wild herbivores and domestic cattle at the Mudumalai Wildlife Sanctuary. However, many of their findings do not concur with each other. One possible cause is the categorization of the 'dry' and 'wet' season according to artificial temporal scales that may not accurately take into consideration the yearly fluctuations in the actual onset of the wet season after the dry one. In this study, carried out between May 1999 and August 1999, we use the 'Cox-Stuart test for trend'. This kind of analysis is likely to give a more accurate picture of the natural process because it does not depend on the rigid categorization of the seasons.

\section{Methodology}

The study area: Situated between $11^{0} 32^{\prime}-11^{0} 93$ 'N \& 76022'-76 ${ }^{0} 43^{\prime} \mathrm{E}$ the study area comprises the Mudumalai Wildlife Sanctuary and National Park and the Sigur Reserve Forest.
Elevations vary between $900-1,000 \mathrm{~m}$ above mean sea level. Temperatures are mild throughout the year. There is a decreasing rainfall from the western side $(1,800 \mathrm{~mm} /$ year $)$ to the eastern side $(600 \mathrm{~mm} /$ year). A high diversity of vegetation types has been observed (Sukumar et al., 1992). The seasons have been classified into three broad categories similar to that used by Watve (1992): the dry (January to April), the first wet (May to August) and the second wet (October to December) seasons. Season-wise temperature and rainfall data for 1999 are summarized in Table 1.

Hosts sampled: Chital (Axis axis), Gaur (Bos gaurus), Elephant (Elephas maximus) and domestic cattle.

Coprological study: Helminth eggs per gram of faeces (e.p.g.) has been used as an index of helminth load. A representative sample of approximately $2 \mathrm{~g}$ was collected from clearly demarcated, fresh dung piles voided by the target species. Samples were collected in labeled, pre-weighed containers having $10 \mathrm{ml}$ of $10 \%$ formalin between 0700 and $0900 \mathrm{hr}$ daily. The exact weight of faeces collected was calculated by subtracting the weight of the empty container with formalin from the weight of container containing the dung sample in formalin. The intensity of helminth infection was determined by the quantitative sedimentation-floatation technique developed and standardized by Watve (1992). Prevalence of strongyle genera was calculated using data obtained from larval cultures. Samples for larval cultures were collected separately in cloth bags, kept moist and cultured in the laboratory within 12-15 hours after collection. Larval cultures for third stage (infective) strongyle larvae were done as per Roberts and Sullivan (1949). Larvae were identified with the help of the keys provided by Dikmans and Andrews (1933), Keith (1953) and Davies (1984). Larvae cultured from Elephant dung were identified by measurements given by Raman (unpub. data).

Habitat-wise comparisons were only possible in the case of Chital. In the case of other species of wild herbivores we had very low sample sizes from scrub areas and in the case of cattle it was not possible to differentiate between animals that grazed in scrub and dry deciduous forests. While the helminth loads of Chital in scrub forest without cattle was studied, all the samples were collected in only two sampling efforts and thus were not analysed for seasonal trends of helminth loads.

Terminology: Helminth loads have been expressed in terms of eggs per gram of faeces (e.p.g.). Here the term has been 
broadened to include larvae of lungworms.

Statistics: The Cox-Stuart test for trend was done as per Conover (1971).

\section{Results}

The mean and median helminth loads observed in the host species studied are summarized in Table 2. The parasite species identified in the various hosts are given in Table 3. Significant upward trends in helminth loads were observed in the case of Elephants, Gaur and cattle. While the seasonal trend in Chital was absent in the dry deciduous forest areas, irrespective of the presence of sympatric cattle, there was a significant downward trend in scrub forest areas with cattle grazing (Table 4).

\section{Discussion}

In general, in environments affected by the monsoons, hosts have shown an increase in helminth loads during the rainy season. Bhatt (1994) found significantly higher helminth loads in all wild herbivores sampled during the southwest monsoon as compared to the dry season. This increase can be attributed to numerous causes like increased survival of larvae after the rains as indicated by increased pasture larval burdens (Raman, 1992), increases in intermediate host populations (Taylor, 1949), the reactivation of arrested larvae within the host with the onset of favourable conditions (Schad et al., 1973). Another reason for increased infection during rains is that heavy rains may wash faeces into aggregations thereby concentrating the infective larvae and increasing chances of host acquiring a massive infective dose (Gordon, 1948).

This expected upward trend of helminth densities was seen in three species sampled - Elephants, Gaur and cattle. The increase in helminth loads during the wet season was in agreement with the findings of Bhatt (1994).

When Chital populations were taken, as a whole, there was no apparent trend in helminth loads. The lack of any trend was also found in Chital populations from the dry deciduous forest areas, with and without cattle grazing. In the scrub area, however, there was a significant downward trend with egg loads decreasing as the dry season progressed into the wet season. This is a finding, which is contrary to expectation. However, it can be explained if worm loads in Chital are more governed by host resistance as compared to contact with infective stages of the parasite. In the scrub forest, the mean biomass of grass during the dry season was found to be very low $\left(156.9 \mathrm{~g} / \mathrm{m}^{2}\right)$ compared to the first wet season $\left(405 \mathrm{~g} / \mathrm{m}^{2}\right)$ and second wet season $\left(524.1 \mathrm{~g} / \mathrm{m}^{2}\right)$ (Baskaran, 1998). Since immunocompetence is affected by nutritional state (Rolston, 1992; Lyles \& Dobson, 1993), as the rainy season progressed, the increased growth in vegetation could reduce nutritional stress and thus improve overall resistance to helminth infections. This may be the case with Chital found in scrub forest environments in the dry season, especially if there is additional competition for resources by cattle. Grass biomass in the dry deciduous forest remains high $\left(>500 \mathrm{~g} / \mathrm{m}^{2}\right)$ in all seasons (Baskaran, 1998). Thus, trends in helminth loads are probably absent in the case of chital in the dry deciduous areas as the higher moisture levels there (Table 1) assure sufficient forage throughout the year. Our hypothesis to explain the interspecific differences in the seasonal trends of helminth loads is supported by our previous findings (Dharmarajan, 2000; Dharmarajan et al., in review). Our hypotheses to explain the seasonal trends in helminth loads, in Chital, in different habitats are also supported by our previous findings (Dharmarajan et al., 2003 a, b). As with everything in ecology, however, the inter-relationship various factors are likely to be complex. Some of these possible interactions are summarized in Figure 1.

\section{Conclusion}

It seems clear that Gaur and Elephants seem to be affected by seasonal factors in ways similar to cattle. The observed upward trends in all these species are likely to be mainly due to improved larval survivability as the wet season progresses. However, Chital seem to be more affected by nutritive status and resource availability than by prevalence of infective stages of their parasites (larvae and/or eggs) in the environment.

\section{REFERENCES}

Baskaran N. (1998). Ranging and resource utilization by Asian elephant (Elephas maximus Linnaeus) in Nilgiri Biosphere Reserve, South India, Ph.D. thesis, submitted to Bharathidasan University, Tamil Nadu.

Bhatt, N. (1994). Disease profile in wild herbivores. M.V.Sc. Thesis submitted to Tamil Nadu Veterinary and Animal Sciences University, Chennai, Tamil Nadu.

Conover, W.J. (1971). Practical Non-parametric Statistics. John Wiley and Sons, Inc., New York.

Davies, E.T. (Editor) (1984). Manual of Veterinary Investigation. $3^{\text {rd }}$ edition. Volume 2. Ministry of Agriculture, Fisheries and Food, Her Majesty's Stationary Office, London, 173-175pp.

Dharmarajan, G. (2000). Epidemiology of helminths in wild and domestic herbivores at the Mudumalai Wildlife Sanctuary, Tamil Nadu. M.V.Sc. Thesis, submitted to Tamil Nadu University of Veterinary and Animal Sciences, Chennai, Tamil Nadu,

Dharmarajan, G., M. Raman and M.C. John (2003 a). The effects of cattle grazing and habitat on helminth loads in Chital (Axis axis) in the Mudumalai Wildlife Sanctuary, Southern India. Journal of the Bombay Natural History Society 100(1): 58-64.

Dharmarajan, G., M. Raman and M.C. John (2003b). Effect of cattle and habitat on helminth community structure of chital. Indian Veterinary Journal 80(10): 984-987.

Dharmarajan, G., M. Raman and M.C. John (In press). Are worms affected by host ecology? A perspective from Mudumalai Wildlife Sanctuary, Southern India. Journal of the Bombay Natural History Society (Accepted May 2002).

Dikmans, G. and J.S. Andrews (1933). Keys to the identification and differentiation of third stage infective larvae of strongyle species. Transactions of the American Microbiologists Society 52: 1.

Foreyt, W.J. and D.O. Trainer (1980). Seasonal parasitism changes in two populations of white-tailed deer in Wisconsin. Journal of Wildlife Management 44: 758-764.

Gordon, H.M. (1948). The epidemiology of parasitic diseases, with special reference to studies with nematode parasites of sheep. Australian Veterinary Journal 24: 17-45.

Horak, I.G. (1981). Seasonal incidence of the major nematode genera recovered from sheep, cattle, Impala and Blesbok in the transval. Journal of the South African Veterinary Association 52: 213-223.

Keith, R.K. (1953). The differentiation of the infective larvae of some common nematode parasites of cattle. Australian Journal of Zoology 1: 223-235. 
Table 1. Season wise meteorological data for scrub and dry deciduous habitats collected from the scrub forest (Masinagudi) and dry deciduous forest (Kargudi) areas at the Mudumalai Wildlife Sanctuary in 1999.

\begin{tabular}{|c|c|c|c|c|c|c|c|c|}
\hline \multirow[t]{3}{*}{ Season } & \multicolumn{4}{|c|}{ Scrub forest (Masinagudi) } & \multicolumn{4}{|c|}{ Dry deciduous (Kargudi) } \\
\hline & \multirow{2}{*}{\multicolumn{2}{|c|}{$\begin{array}{l}\text { Rainfall } \\
\text { Monthly Total } \\
\text { Av. (mm) } \\
(\mathrm{mm}) \quad\end{array}$}} & \multicolumn{2}{|c|}{ Temperature } & & \multicolumn{2}{|c|}{ Temperature } \\
\hline & & & $\begin{array}{l}\text { Av. } \\
\text { Max. } \\
\left({ }^{\circ} \mathrm{C}\right)\end{array}$ & $\begin{array}{l}\text { Av. } \\
\text { Min. } \\
\left({ }^{\circ} \mathrm{C}\right)\end{array}$ & $\begin{array}{l}\text { Monthly } \\
\text { Av. } \\
\text { (mm) }\end{array}$ & $\begin{array}{l}\text { Total } \\
(\mathrm{mm})\end{array}$ & $\begin{array}{l}\text { Av. } \\
\text { Max. } \\
\left({ }^{\circ} \mathrm{C}\right)\end{array}$ & $\begin{array}{l}\text { Av. } \\
\text { Min. } \\
\left({ }^{\circ} \mathrm{C}\right)\end{array}$ \\
\hline Dry & 24.47 & 97 & 30.75 & 17.43 & 29.45 & & 29.13 & 16.63 \\
\hline First & 75.64 & 302.57 & 28.00 & 19.33 & 126.68 & & 27.56 & 18.50 \\
\hline Second Wet & 104.81 & 419.22 & 27.08 & 17.73 & 98.05 & 392.20 & 27.02 & 17.28 \\
\hline Annual & 68.30 & 819.65 & 28.61 & 18.16 & 84.73 & 1016.70 & 27.90 & 17.47 \\
\hline
\end{tabular}

Table 2. Helminth loads in wild herbivores and domestic cattle at the Mudumalai Wildlife Sanctuary, Tamil Nadu.

\begin{tabular}{|c|c|c|c|c|c|}
\hline Host Species & $\begin{array}{l}\text { Sample } \\
\text { Size }\end{array}$ & $\begin{array}{l}\text { Percent } \\
\text { Infected }\end{array}$ & $\begin{array}{l}\text { Median } \\
\text { Load } \\
\text { (epg) }\end{array}$ & $\begin{array}{l}\text { Mean } \\
\text { Load } \\
(e p g)\end{array}$ & Variance \\
\hline Chital in Scrub with cattle & 55 & 80.00 & 4 & 5.64 & 106.16 \\
\hline Chital in Scrub with no cattle* & 39 & 69.23 & 1 & 2 & 18.68 \\
\hline Chital in D. deciduous with cattle & 60 & 78.33 & 2 & 2.95 & 54.01 \\
\hline $\begin{array}{l}\text { Chital in D. deciduous with } \\
\text { no cattle }\end{array}$ & 60 & 70.00 & 2 & 2.4 & 48.38 \\
\hline Gaur & 54 & 85.19 & 3 & 11.93 & 684.82 \\
\hline Elephant & 34 & 85.29 & 3.5 & 4.15 & 45.04 \\
\hline Cattle & 56 & 91.07 & 5.5 & 7.84 & 156.35 \\
\hline
\end{tabular}

epg - eggs per gram of faeces; ${ }^{*}$ - Not analysed for seasonal effects.

Table 3. Helminth species identified in the hosts sampled

\begin{tabular}{|c|c|c|}
\hline Host & $\begin{array}{l}\text { Parasite } \\
\text { Species identified }\end{array}$ & Total \\
\hline Chital & $\begin{array}{l}\text { Cooperia sp., Cotylophoron sp., Dicrocoelium sp., } \\
\text { Haemonchus sp., Mecistocirrus sp., Muellerius sp., } \\
\text { Nematodirus sp., Oesophagostomum sp., Strongyloidus sp., } \\
\text { Trichuris sp., Trichostrongylus sp., Anoplocephalid, } \\
\text { Ascarid, Fluke, Hookworm and Spiruroid }\end{array}$ & 16 spp. \\
\hline Gaur & $\begin{array}{l}\text { Haemonchus sp., Mecistocirrus sp., Muellerius sp., } \\
\text { Oesophagostomum sp., Protostrongylus sp., Strongyloidus } \\
\text { sp., Trichuris sp., Trichostrongylus sp., Anoplocephalid, } \\
\text { Fluke, Hookworm and Spiruroid }\end{array}$ & 12 spp. \\
\hline Elephant & $\begin{array}{l}\text { Bathmostom sp., Decrusia sp., Quilonia sp., Murshidia sp., } \\
\text { Anoplocephalid, Fluke and Spiruroid }\end{array}$ & \\
\hline Cattle & $\begin{array}{l}\text { Cooperia sp., Dicrocelium sp., Haemonchus sp., } \\
\text { Mecistocirrus sp., Moniezia sp., Nematodirus sp., } \\
\text { Oesophagostum sp., Strongyloidus sp., Trichuris sp., } \\
\text { Trichostrongylus sp., Ascarid, Fluke and Hookworm }\end{array}$ & 13 spp. \\
\hline
\end{tabular}

Lyles, A.M. and A.P. Dobson (1993). Infectious disease and intensive management: population dynamics, threatened hosts and their parasites. Journal of Zoo Wildlife Medicine 24: 315-326.

Poulin, R. (1996). The evolution of life history strategies in parasitic animals. Advances in Parasitology 37: 107-134.

Raman, M. (1992). Studies on the epidemology of the gastro-intestinal helminths in dairy animals and experimental abomosal nematode infection in cattle. Ph.D. Thesis, submitted to Tamilnadu University of Veterinary and Animal Sciences, Chennai, Tamilnadu,

Roberts, F.H.S. and P.J .O'sullivan (1949). Methods for egg counts and larval cultures for strongyles infecting the gastro-intestinal tract of cattle. Australian Journal of Agricultural Research 1: 99-103.

Robbins, C.T. (1993). Wildlife Feeding and Nutrition. Academic Press, Inc. San Diego, USA, 238-239pp.

Rolston, H. (1992). Ethical responsibilities towards wildlife. Journal of the American Veterinary Medical Association 200: 618-622.

Schad, G.A., A.B. Chowdbury, C.G. Dean, V.K. Kochar, T.A. Nawalinski, J. Thomas and J.A. Tonascia (1973). Arrested development in human hookworm infection: an adaptation to a seasonally unfavourable external environment. Science 180: 502-504. Soulsby, E.J.L. (1982). Helminth, arthropods and protozoa of domestic animals. 7th edition. Baillerie Tindall Co., UK.

Sukmar, R., H.S. Dattaraja, H.S. Suresh, J. Radhakrishnan, R. Vasudevan, S. Nirmala and N.V. Joshi (1992). Long term monitoring of vegetation in a tropical deciduous forest in Mudumalai, Southern India. Current Science 62: 608-616.

Taylor, E.L. (1949). The epidemiology of fascioliasis in Britain. Proceedings of the $14^{\text {th }}$ International Veterinary Congress, London, 2: 81-87 (cited by Soulsby, 1982).

Watve, M.G. (1992). Ecology of host-parasite interactions in a wild mammalian host community in Mudumalai, Southern India, Ph.D. Thesis submitted to Indian Institute of Science, Bangalore.

Waid, D.D., D.B. Pence and R.J. Warren (1985). Effects of season and physical condition on the gastro-intestinal helminth community of white-tailed deer from the Texas Edwards Plateau. Journal of Wildlife Disease 21: 264-273.

\section{ACKNOWLEDGEMENTS}

We thank the Tamil Nadu Forest Department; Mr. A. Udhayan, IFS; late Dr. V. Krishnamurthy (Forest Veterinarian); Mr. A. Desai, Dr. N. Baskaran, Mr. S. Swaminathan (Bombay Natural History Society); Dr. R. Sukumar, Dr. N.V. Joshi (Centre for Ecological Sciences); Dr. G. Rajavelu, Dr. S. Ramesh, Dr. M.G. Jayathangaraj (Madras Veterinary College) and Sachin Ranade.

Table 4. Cox-Stuart Test results for detection of trends in egg per gram of faeces (egg) during the period of study.

\begin{tabular}{llllll}
\hline Host Population & \multicolumn{3}{l}{ Sample Cox- Stuart Test Parameters } & Implication \\
& size & $\mathbf{n}$ & $\mathbf{T}$ & Critical region & \\
\hline Chital: Dry Deciduous without cattle & 60 & 24 & $14^{\text {ns }}$ & $7.19>\mathrm{T}>16.81$ & No trend exists \\
Chital: Dry Deciduous with cattle & 60 & 25 & $16^{\text {ns }}$ & $7.6>\mathrm{T}>17.4$ & No trend exists \\
Chital: Scrub with cattle & 55 & 27 & $8^{*}$ & $8.4>\mathrm{T}>18.6$ & Significant downward trend \\
Gaur & 54 & 25 & $25^{*}$ & $7.6>\mathrm{T}>17.4$ & Significant upward trend. \\
Elephant & 34 & 16 & $15^{*}$ & $4.08>\mathrm{T}>10.92$ & Significant upward trend. \\
Cattle & 56 & 22 & $17^{*}$ & $7.04>\mathrm{T}>14.96$ & Significant upward trend. \\
\hline
\end{tabular}

$\mathrm{n}$ - number of + and -; T - number of $+; \mathrm{ns}-$ not significant $\left(5 \%\right.$ level) ${ }^{*}{ }^{*}$ significant $(5 \%$ level) 


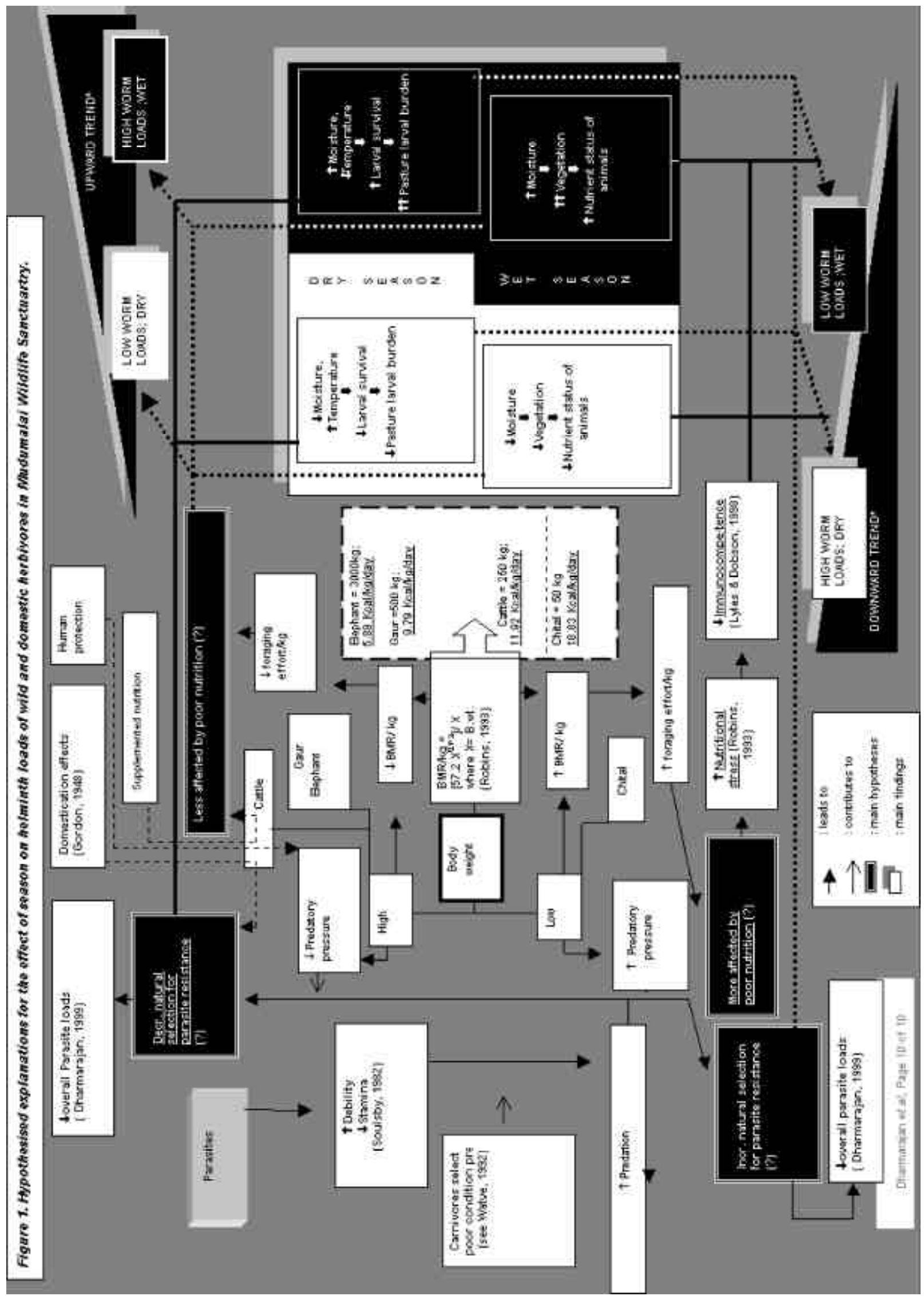

